\title{
PRINCÍPIOS E DIMENSÕES DE COMPETÊNCIAS NA ATUAÇÃO DO OUVIDOR
}

\author{
Luciana Bertachini ${ }^{1}$
}

\section{Resumo}

No âmbito corporativo alguns setores ou políticas de gestão passam atualmente por profundas transformações e mudanças de paradigmas. Há um deslocamento da ênfase em problemas e improdutividade para a preocupação com o bem-estar do ser humano, o que implica impactos na cultura organizacional. Ocorrem transformações de um sistema burocrático para um sistema adaptativo, em que o cidadão estabelece uma relação de mutualidade e parceria com as organizações e seus gestores. Isso significa que há uma transformação: de um paradigma mecanicista para outro, novo e desafiante, o orgânico. O exemplo concreto do modelo orgânico nas empresas ocorre com a instituição de Ouvidorias que atuam como um componente organizacional que favorece a interlocução da instituição com os cidadãos conscientes. Está diretamente relacionada com o amadurecimento da gestão participativa, por acolher e tratar as manifestações, registradas sob a forma de reclamações, denúncias, sugestões, críticas e elogios, elaborando recomendações que são consideradas nas propostas de gestão. A "voz" representada na figura do Ouvidor não é um simples diferencial estratégico, mais do que isso, é parte dos valores da organização, capaz de recomendar e redirecionar o rumo das decisões, pautadas pela transparência, confidencialidade e conduta bio (ética). Destacam-se nesta reflexão os princípios da Ouvidoria, o Código de Ética e as Competências do Ouvidor.

Palavras-chave: Ouvidoria. Competências. Código de Ética. Bioética.

DOI:10.37814/2594-5068.2020v3.p57-68

1 Doutora em Bioética e Ouvidoria. Mestre e especialista em Ciências dos Distúrbios da Comunicação Humana pela Universidade Federal de São Paulo Unifesp/EPM e Conselho Federal de Fonoaudiologia. Especialista em Voz e Motricidade Oral pelo Conselho Federal de Fonoaudiologia e Unifesp/EPM. Fonoaudióloga da Disciplina de Geriatria e Gerontologia da Unifesp/EPM. Membro da Comissão Científica da Revista Bioética do Conselho Federal de Medicina - CFM. Docente da Associação Brasileira de Ouvidores/Ombudsman - ABO Nacional. Membro do Comitê de Ouvidorias da Abrarec - Associação Brasileira de Relações Empresas-Clientes. Diretora de Publicações da Associação Brasileira de Ouvidores/Ombudsman - ABO Nacional. 


\begin{abstract}
At the corporate level, some management sectors or policies are currently undergoing profound changes and paradigm shifts. There is a shift from the emphasis on problems and unproductiveness to concern for human well-being, which implies impacts on organizational culture. Transformations occur from a bureaucratic system to an adaptive system, in which the citizen establishes a relationship of mutuality and partnership with organizations and their managers. This means that there is a transformation: from one mechanistic paradigm to another, new and challenging one, the organic one. The concrete example of the organic model in companies occurs with the institution of Ombudsman's offices that act as an organizational component that favors the institution's dialogue with conscious citizens. It is directly related to the maturation of participatory management, by receiving and handling the manifestations, registered in the form of claims, complaints, suggestions, criticisms and compliments, making recommendations that are considered in the management proposals. The "voice" represented in the figure of the Ombudsman is not a simple strategic differential, more than that, it is part of the organization's values, able to recommend and redirect the direction of decisions, based on transparency, confidentiality and bio (ethical) conduct. This reflection highlights the principles of the Ombudsman, the Code of Ethics and the Ombudsman's competences.
\end{abstract}

Keywords: Ombudsman. Skills. Code of Ethics. Bioethics. 


\section{INTRODUÇÃO}

O sociólogo Max Weber deixou um grande legado intelectual para o entendimento de várias outras áreas do conhecimento. Entre os vários conceitos apresentados pelo sociólogo, está um desenvolvido para explicar o funcionamento das Organizações, sobretudo no que se refere à ética. No início do século, Weber classificou as organizações em três tipos: as "carismáticas", as "tradicionais" e as "burocráticas". As instituições carismáticas são muito personalistas, se confundem com uma pessoa física, sendo o modo mais clássico de exercer o poder. As tradicionais baseiam-se nos costumes e tradições culturais de um determinado grupo ou sociedade, sendo representadas pelas figuras de patriarcas, em sociedades antigas, ou pelo senhor feudal na Idade Média. A principal característica é o patrimonialismo. As organizações burocráticas tornam-se cada vez mais impessoais, se definem como estruturas formais, sem rosto, que aparecem como carentes de alma e de sentimentos. Daí o sentido pejorativo que por todo o curso dos últimos séculos foi adquirindo o termo "burocracia". A burocracia é, de algum modo, o oposto da ética. Não é por acaso que foram por muito tempo considerados termos antagônicos. Falar de ética das instituições parecia um contrassenso.

Durante os anos 1980, produziu-se uma autêntica revolução na teoria das instituições empresariais, segundo a qual os valores e a ética passaram de elementos completamente alheios à teoria empresarial para se constituírem em uma de suas partes fundamentais. GRACIA (2010) comenta que foi Max Weber quem primeiro chamou atenção para isso, revelando a importância da ética na teoria empresarial. Sua grande expansão teve lugar nos anos 1990, produzindo outra novidade importante: passou da "ética das empresas" a "ética das organizações", devendo equacionar os fins lucrativos com os deveres, como os que se convencionou chamar "deveres de boa cidadania" (JENNINGS, 1990).

A partir da perspectiva ética adotada nas organizações, se destacaram as iniciativas de humanizar as relações de trabalho, alinhadas aos direitos, valores e princípios. A natureza da atividade da Ouvidoria está diretamente ligada a compreensão e respeito às necessidades, direitos e valores das pessoas. Considerando que por necessidades, direitos e valores entende-se não apenas questões materiais, mas também questões de ordem moral, intelectual e social, e que direitos só têm valor quando efetivamente reconhecidos.

\section{DESENVOLVIMENTO}

A Ouvidoria atua como uma instância que busca humanizar as relações conflituosas oriundas de "pontos de desequilíbrio" no contexto institucional. Neste contexto as relações humanas constituem um tema delicado no campo das questões éticas, estando o Ouvidor posicionado nos espaços de conflitos, interagindo com diferentes realidades, devendo exercitar sua acurada gama de percepções e boa visão sistêmica da organização.

As relações conflituosas, sobretudo de natureza crônica ou reincidente, acentuam a vulnerabilidade daqueles que não têm voz ativa na dinâmica institucional, gerada pela assimetria de poderes e 
pela relação de dependência dos sujeitos de limitada autonomia, marcada pela desinformação, medo ou descrédito nas relações de trabalho, ou mesmo de consumo. Nesse contexto, surge a Bioética como um sinal de esperança, o que não diminui a necessidade de ética no âmbito das organizações (PESSINI; BERTACHINI, 2010). A Bioética exige que haja questionamento sobre o caráter humanizador ou desumanizador de certas práticas que envolvem valores, princípios e regras e sobre as repercussões previsíveis, especialmente suas consequências no modo de viver em sociedade (VERSPIEREN, 1993). Os valores traduzem-se nos comportamentos - campo prático das Ouvidorias.

No tratamento individual dos problemas, algumas soluções podem ser aplicadas no coletivo (BARREIRO; HOSSNE; PENTEADO SOBRINHO, 2011). Nessa linha, é lícito pensar que a Ouvidoria promove a qualificação do interesse individualizado com expressão de um interesse maior, coletivo. Essa condição de extrair o interesse coletivo da manifestação privada, posto que uma reclamação valha em si mesma, transcende o emissor e o destinatário, edifica o equilíbrio e contribui decisivamente para que a Ouvidoria venha a ser "um campo ético de interlocução e humanização" dentro das organizações.

\subsection{O papel das Ouvidorias nas organizações}

Na visão de FORNAZARO (2019), a Ouvidoria, estabelecida através do seu processo histórico de 210 anos (começou em 1809, na Suécia), tem sido avaliada, com justa razão, pelos impactos que provoca na transparência das atividades, pelo fortalecimento da cidadania e dos valores democráticos. Não se pode dizer que uma sociedade seja democrática se seus cidadãos não puderem manifestar eventuais contrariedades, nem receber respostas adequadas às suas queixas. Mas a Ouvidoria, além disso, é um grande instrumento de aperfeiçoamento da gestão.

O respeito aos valores humanos constitui boa parte do eixo de argumentação das práticas da Ouvidoria quando ela evoca uma base sólida de princípios éticos para apresentar seus posicionamentos e recomendações, que não caracterizam proposição de regras, mas interagem com elas permitindo revisões de alcance prático no contexto corporativo. A Ouvidoria implica ouvir "os sujeitos da relação", e, se há escuta, há alguém que está expressando algo com base nos seus valores: uma demanda, um desejo, uma necessidade, ou qualquer outra intenção que o uso da palavra permite a cada sujeito nomear (MARQUES et al., 2005). Essa troca dinâmica de expressões e impressões está no cerne do processo da comunicação da Ouvidoria com a alta direção da organização, que busca, do crescimento da afinidade à redução das diferenças, a ampliação do conhecimento, o desafio às indiferenças (YASBEK, 2010). Para OLIVEIRA (2001), valores podem ser complementares, como são eficiência com justiça, lucro com equidade, e crescimento com solidariedade (OLIVEIRA, 2001, p. 16).

É nesse tempo que podemos partejar o novo, diluir resistências e enfrentar as sombras em que mergulham os conflitos de interesses e impessoalidade com os valores humanos (YASBEK, 2010). Nessa perspectiva, a Ouvidoria cria um ritmo e escuta permanente para que o cidadão consiga expor dificuldades, e a Organização aprimore e atualize suas percepções internas para maior flexibilidade na correção de rumos, com menos danos e mais dignidade.

A implantação das Ouvidorias nas Organizações se justifica no compromisso público que as

60 | Revista Científica da Associação Brasileira de Ouvidores/Ombudsman - Ano 3-n $3-2020$ 
empresas assumem em aplicar suas políticas e princípios éticos norteadores das iniciativas de valorização dos seus clientes e colaboradores, tornando-se uma instância diferenciada por oficializar e instituir mecanismos específicos voltados para a comunicação, relacionamentos humanos e apoio à gestão interna, mantendo acurada a percepção da realidade sistêmica (BERTACHINI, 2013). É interessante constatar que, quando há o amadurecimento da organização, a alta direção acolhe com interesse as recomendações da Ouvidoria, como "fonte ética" e segura de informações.

Ao impulsionar mudanças no contexto organizacional, as Ouvidorias certificam aos gestores o fato de que "não temos uma organização de papel" e que o potencial de contribuição de suas atividades existe por conta do que é sua maior força: a convivência com a vida real dos cidadãos e com os seus valores inerentes, como lembra OLIVEIRA (2005, p. 54).

Trabalhando com questões éticas, o potencial de transformação intrínseco às Ouvidorias é grande, mas sua inserção nas organizações, seu mandado, sua estratégia de trabalho e sua capacidade de ação ainda implicam muito a conquistar e outro tanto a ser construído. Não obstante os conflitos éticos que ocorrem nos meandros das organizações, há outros desafios, na medida em que a Ouvidoria se depara com discrepâncias e contradições. Esse cenário suscita perguntas cujas respostas repercutem diretamente na qualidade e na lógica de trabalho das Ouvidorias nas organizações.

O desafio do Ouvidor é o de mudar aspectos disfuncionais de uma cultura organizacional, "fazer com que as pessoas percebam que, apesar de sermos representantes do cidadão consciente e defendermos os seus direitos, não somos inimigos da empresa [...]". "[...] também dizemos 'não' ao manifestante, mas explicamos por que estamos fazendo isso [...]" (BERTACHINI, 2012a, p. 14). É muito difícil mudar procedimentos arraigados, por isso é fundamental a relação de transparência com os manifestantes, para que possam compreender determinados processos e pareceres conclusivos.

Seríamos ingênuos se acreditássemos na existência de uma instituição perfeita, mas reconhecemos que existem iniciativas corporativas que buscam alinhar rotas de aprimoramento contínuo dos processos, das dinâmicas organizacionais, aperfeiçoando-se e autocorrigindo-se. Para PESSINI e BERTACHINI (2010), não há dúvidas de que as organizações que atribuem às Ouvidorias o cuidado responsável diante da vulnerabilidade e hipossuficiência do cidadão esperam ações inteligentes e competentes. As Ouvidorias são valorizadas por não permitirem "frouxidão moral" no tratamento dos problemas individuais e de interesse organizacional, por demonstrarem posturas éticas, lisura, honestidade e a verdade nos processos em que atuam.

A Ouvidoria se apresenta como uma legítima figura ética, e de maior celeiro de recomendações concretas para a melhoria dos serviços. O que se destaca é o entusiasmo com que os Ouvidores se dedicam ao exercício desta atividade, que vai muito além de ouvir e compreender o cidadão. (BERTACHINI, 2012, p. 14)

Algumas questões sobre Liderança e Governança são importantes em toda e qualquer organização que anseie instituir uma Ouvidoria que possa fomentar sua identidade ética (PESSINI; BERTACHINI, 2010). Nesse contexto, destaco um tema para reflexão: Como superar uma "cultura mecanicista" com vistas à incorporação de uma "cultura orgânica"? 
No âmbito corporativo alguns setores ou políticas de gestão passam atualmente por profundas transformações e mudanças de paradigmas. Há um deslocamento da ênfase em problemas e improdutividade para a preocupação com o bem-estar do ser humano, o que implica impactos na cultura organizacional. Ocorrem transformações de um sistema burocrático para um sistema adaptativo, em que o cidadão estabelece uma relação de mutualidade e parceria com as organizações e seus gestores. Isso significa que há uma transformação: de um paradigma mecanicista para outro, novo e desafiante, o orgânico.

Em organizações marcadas por culturas mecanicistas, as tarefas são rígidas, previsíveis e imutáveis. A criatividade, além de não ser necessária, é desencorajada, uma vez que ela ameaça o contexto estável e o estilo previsível de agir. Na cultura de paradigma mecanicista, o que importa é a tarefa ou o processo resolvido, não tanto a pessoa que resolve e soluciona. Pergunta-se: ouvir a pessoa para quê? Perda de tempo? O que importa são os resultados!

A resolução de conflitos acontece por meio da supressão e da coerção, não pela negociação e pelo diálogo, propósitos da Ouvidoria. Além disso, as relações são marcadas por uma "afetividade esparramada", que facilmente encobre incompetências e provoca injustiças, contrariamente ao modelo orgânico, em que a ética permeia o respeito pelas competências e pessoas.

Nas organizações de culturas orgânicas, o foco não está prioritariamente nas regras e nos regulamentos, sempre necessários, mas na inovação, na criatividade e no feedback avaliativo para manter a organização respondendo adequadamente ao contexto de mudanças constantes. O processo decisório é proativo, antes que reativo voltado à solução de crises. Administrações orgânicas consistem de pessoas que, longe de serem agentes passivos, se antecipam aos tempos e fatos. São articuladoras de uma visão, estratégias de ação, avaliação e planejamento do futuro organizacional.

O exemplo concreto do modelo orgânico nas empresas ocorre com a instituição de Ouvidorias que atuam como um componente organizacional que favorece a interlocução da instituição com os cidadãos (consumidores e colaboradores). Está diretamente relacionada com o amadurecimento da gestão participativa, por acolher e tratar as manifestações, registradas sob a forma de reclamações, denúncias, sugestões, críticas e elogios, elaborando recomendações que são consideradas nas propostas de gestão. A "voz" representada na figura do Ouvidor não é um simples diferencial estratégico, mais do que isso, é parte dos valores da organização, capaz de recomendar e redirecionar o rumo das decisões, pautadas pela transparência, confidencialidade e conduta ética.

Seria diminuta uma ação de Ouvidoria essencialmente técnica, burocrática e distante, uma vez que o diferencial de seu aprimoramento está na inclusão de reflexões e posicionamentos éticos que alimentam a coerência de suas condutas na promoção de mudanças benéficas em meio aos contextos críticos. De certa maneira, a Ouvidoria "arranha o verniz da superficialidade". Como expõe CORTELA (2007): "Deixar falar, saber ouvir, sensibilizar-se com o outro naquilo que o ameaça e em seus reais interesses é considerar sua história".

Diante do exposto, é possível pensar que as Ouvidorias trabalham com desafios éticos paralelamente aos parâmetros culturais da Organização, bem como com a sensibilização de suas lideranças. Parece justo afirmar que o sentido de "Ouvir o outro para olhar-se por dentro", como uma visão (bio)ética da Ouvidoria na cultura organizacional, possa trazer benefícios para o aprimoramento da administração orgânica no âmbito corporativo, realçando os valores humanos. 


\subsection{Princípios da Ouvidoria e Código de Ética do Ouvidor}

Segue daí a importância de revisitar os princípios clássicos da Ouvidoria visando o tratamento ético das suas atribuições e práticas. Independentemente do âmbito de atuação, as Ouvidorias são pautadas pelos princípios que balizam suas concepções e finalidades, exemplificados pelo Decreto do Estado de São Paulo n 60.399, de 29 de abril de 2014, que dispõe sobre a atividade das Ouvidorias instituídas pela Lei $\mathrm{n}^{\circ} 10.294$.
Dos Princípios:
I - independência e autonomia para o exercício de suas atribuições sem qualquer ingerên- cia, inclusive político-partidária, visando garantir os direitos do usuário do serviço público; II - transparência na prestação de informações de forma a garantir a exata compreensão do usuário sobre as repercussões e abrangência do serviço público;
III - confidencialidade para a proteção da informação de modo a assegurar a intimidade, a vida privada, a honra e a imagem do usuário;
IV - imparcialidade e isenção necessárias para compreender, analisar e buscar soluções para as manifestações, bem como formular críticas e recomendações;
$\mathrm{V}$ - acolhimento e acessibilidade, assegurando o atendimento respeitoso e a preservação da dignidade humana.

Os princípios da Ouvidoria vão subsidiar a construção de um ambiente ético para o tratamento das informações, questionamentos e críticas dos usuários dos serviços públicos e privados. Tais princípios zelam pelos direitos de privacidade e sigilo das informações, bem como pelo direito de acesso às informações.

Consciente de seu papel, a Associação Brasileira de Ouvidores/Ombudsman - ABO aprovou, em 1997, no seu II Encontro Nacional, o Código de Ética do Ouvidor, visando a preservar os princípios que regem a Ouvidoria, expressando os valores que devem nortear a atuação dos Ouvidores/ Ombudsman e conscientizando os cidadãos sobre o alcance dessa função e de suas obrigações para com a comunidade. São 23 os artigos que o compõem, relacionados com a postura que o Ouvidor deve adotar. Dentre esses pontos, salienta-se o reconhecimento de que os Ouvidores/ Ombudsman devem defender intransigentemente os direitos inerentes à pessoa humana: agir com integridade, transparência e respeito; exercer suas atividades com independência e autonomia, de forma ágil e precisa, buscando a correção dos procedimentos incorretos. Esse Código de Ética representa um compromisso dos Ouvidores/Ombudsman de exercerem suas funções, respeitando fundamentos imprescindíveis para quem se propõe a atuar em defesa dos interesses do cidadão, nas instituições públicas ou privadas (VISMONA et al., 2000).

Proposta aprovada na Assembleia Geral Extraordinária, convocada para essa finalidade, realizada em Fortaleza - CE, no dia 19/12/97.

Considerando que a natureza da atividade da Ouvidoria está diretamente ligada à compreensão e respeito às necessidades, direitos e valores das pessoas.

Considerando que por necessidades, direitos e valores entende-se não apenas questões materiais, mas também questões de ordem moral, intelectual e social, e que direitos só têm valor quando efetivamente reconhecidos.

Considerando que, no desempenho de suas atividades profissionais e dependendo da forma como essas sejam desempenhadas, os Ouvidores/Ombudsman podem efetiva- 
mente fazer aplicar, alcançando esses direitos.

Considerando que a função do Ouvidor/Ombudsman visa o aperfeiçoamento do Estado, da Empresa, e a busca da eficiência e da austeridade administrativa.

Finalmente, considerando que, no exercício das suas atividades, os Ouvidores/Ombudsman devem defender intransigentemente os direitos inerentes da pessoa humana, balizando suas ações por princípios éticos, morais e constitucionais.

Os membros da ABO - Associação Brasileira de Ouvidores resolvem instituir o Código de

Ética, nos termos enumerados a seguir:

1. Preservar e respeitar os princípios da Declaração Universal dos Direitos Humanos, da Constituição Federal e das Constituições Estaduais.

2. Estabelecer canais de comunicação de forma aberta, honesta e objetiva, procurando sempre facilitar e agilizar as informações.

3. Agir com transparência, integridade e respeito.

4. Atuar com agilidade e precisão.

5. Respeitar toda e qualquer pessoa, preservando sua dignidade e identidade.

6. Reconhecer a diversidade de opiniões, preservando o direito de livre expressão e julgamento de cada pessoa.

7. Exercer suas atividades com independência e autonomia.

8. Ouvir seu representado com paciência, compreensão, ausência de pré-julgamento e de todo e qualquer preconceito.

9. Resguardar o sigilo das informações.

10. Facilitar o acesso à Ouvidoria, simplificando seus procedimentos, agindo com imparcialidade e justiça.

11. Responder ao representado no menor prazo possível, com clareza e objetividade.

12. Atender com cortesia e respeito as pessoas.

13. Buscar a constante melhoria das suas práticas, utilizando eficaz e eficientemente os recursos colocados à sua disposição.

14. Atuar de modo diligente e fiel no exercício de seus deveres e responsabilidades.

15. Promover a reparação do erro cometido contra o seu representado.

16. Buscar a correção dos procedimentos errados, evitando a sua repetição, estimulando, persistentemente, a melhoria da qualidade na administração em que estiver atuando.

17. Promover a justiça e a defesa dos interesses legítimos dos cidadãos.

18. Jamais utilizar a função de Ouvidor para atividades de natureza político-partidária ou auferir vantagens pessoais e/ou econômicas.

19. Respeitar e fazer cumprir as disposições constantes do "Código de Ética", sob pena de sofrer as sanções, que poderão ser de advertência, suspensão ou expulsão dos quadros associativos, conforme a gravidade da conduta praticada, devendo a sua aplicação ser comunicada ao Órgão ou Empresa no qual o Ouvidor exerça suas atividades.

20. As sanções serão impostas pela Diretoria Executiva da $A B O$, ex-officio ou mediante representação, com direito a recurso ao Conselho Deliberativo, em prazo de 15 dias após a imposição da penalidade aos membros do quadro associativo.

21. As Seções Estaduais poderão ter o seu "Código de Ética e Conduta", que deverão ser submetidos à apreciação do Conselho Deliberativo da ABO.

22. As sanções impostas pelas Seções Estaduais da $A B O$ poderão ser objeto de recurso ao Conselho Deliberativo da ABO, no prazo de 15 dias.

23. Os procedimentos para a avaliação e aplicação das sanções serão definidos por Resolução da Diretoria Executiva.

Fortaleza, 19 de dezembro de 1997.

\subsection{Competências do Ouvidor}

É de suma importância revisitar as considerações de YASBEK (2010) quando afirma que, na

64 | Revista Científica da Associação Brasileira de Ouvidores/Ombudsman - Ano 3 - n $3-2020$ 
Ouvidoria, a relação dialógica implica o desenvolvimento de uma série de competências específicas por parte dos profissionais que ali trabalham. Eles precisam, na opinião do autor, "saber ouvir" na perspectiva do outro (e não "colocando-se no lugar do outro"), reconhecer os motivos desse outro (ainda que dele discorde ou não veja em seus argumentos "amparo regulamentar"). Nas palavras do autor:

O dialogismo [...] não significa mero intercâmbio de dois egos habitados de linguagem. A fala não é propriedade privada de um eu, mas algo que se transforma continuamente de uma pergunta para uma resposta e vice-versa. [...]

Mesmo não havendo um documento único que uniformize a descrição de competências das Ouvidorias públicas e privadas, constam abaixo os compromissos essenciais que caracterizam as atividades das Ouvidorias brasileiras (BERTACHINI, 2007a):

I. Escuta qualificada (empática e ativa).

II. Confiabilidade no tratamento da demanda e nas orientações fornecidas.

III. Identificação das opções para avanço na questão apresentada.

IV. Contribuição na mediação de conflitos ou na resolução do problema com as partes envolvidas.

V. Acolhimento e intervenção de demandas que infrinjam o Código de Ética da Instituição, seus valores, suas normas e procedimentos.

VI. Recomendação às áreas corporativas quanto às demandas que possam harmonizar os interesses coletivos visando melhorias nos mecanismos de solução definitiva dos problemas.

VII. A autonomia é um dos seus principais pilares, possibilitando o "livre trânsito" da Ouvidoria dentro da organização, em conformidade com as normas e regulamentos pertinentes.

As Ouvidorias colaboram para os processos de gestão, podendo compor comissões ou conselhos de diretoria para assessorar em deliberações de planos de ação que buscam atender aos interesses dos consumidores. Atuam na recomendação de ações preventivas, pedagógicas (orientando os cidadãos) e intervencionistas com programas para correção de processos administrativos e fomento de novas posturas ético-profissionais, visando à harmonia de relacionamentos humanos, que se refletem no chamado "clima institucional".

\subsection{A Ouvidoria e a Classificação Brasileira de Ocupações (CBO)}

Em abril de 2013, o Ministério do Trabalho e Emprego publicou, para surpresa de muitos Ouvidores, a Classificação Brasileira de Ocupações (CBO), contemplando a atividade do Ouvidor. Considerou-se um importante passo para a emancipação das Ouvidorias no cenário brasileiro de ocupações profissionais. Vejamos algumas informações técnicas a respeito da CBO 2002.

A Classificação Brasileira de Ocupações - CBO, instituída por portaria ministerial $n^{\circ} 397$, de 9 de outubro de 2002, tem por finalidade a identificação das ocupações no mercado de trabalho, para fins classificatórios junto aos registros administrativos e domiciliares. É o documento normalizador do reconhecimento, da nomeação e da codificação dos títulos e conteúdos das ocupações 
do mercado de trabalho brasileiro. A Classificação Brasileira de Ocupações descreve e ordena as ocupações dentro de uma estrutura hierarquizada que permite agregar as informações referentes à força de trabalho, segundo características ocupacionais que dizem respeito à natureza da força de trabalho (funções, tarefas e obrigações que tipificam a ocupação) e ao conteúdo do trabalho (conjunto de conhecimentos, habilidades, atributos pessoais e outros requisitos exigidos para o exercício da ocupação).

Três conceitos sustentam a construção da nomenclatura:

- Ocupação: refere-se ao que existe no mundo concreto das atividades exercidas pelo cidadão em um emprego ou outro tipo de relação de trabalho (autônomo, por exemplo). É a agregação de empregos ou situações de trabalho similares quanto às atividades realizadas. O título ocupacional, em uma classificação, surge da agregação de situações similares de emprego e/ou trabalho.

- Emprego ou situação de trabalho: refere-se ao conjunto de atividades desempenhadas por uma pessoa, com ou sem vínculo empregatício.

- Competências: refere-se às atividades mobilizadas para o desempenho das atividades do emprego ou trabalho.

O conceito de competência tem duas dimensões:

- Nível de competência: refere-se à complexidade, amplitude e responsabilidade das atividades desenvolvidas no emprego ou outro tipo de relação de trabalho.

- Domínio (ou especialização) da competência: relaciona-se às características do contexto do trabalho como área de conhecimento, função, atividade econômica, processo produtivo, equipamentos, bens produzidos que identificarão o tipo de profissão ou ocupação.

Pode-se, ainda, conceituar a ocupação como o conjunto articulado de funções, tarefas e operações destinadas à obtenção de produtos ou serviços. Representado pelo código total de quatro números, o Ouvidor brasileiro foi oficializado pelo Código 1423 (Ouvidor).

Entre as competências do Ouvidor apresentadas pela CBO 2002 - Ministério do Trabalho e Emprego, destacam-se: liderar pessoas; demonstrar capacidade de negociação; tomar decisões; demonstrar capacidade de abstração; trabalhar em equipe; demonstrar capacidade de raciocínio analítico; demonstrar capacidade de síntese; demonstrar capacidade de relacionamento interpessoal; demonstrar flexibilidade; agir com empatia; demonstrar capacidade de organização; demonstrar habilidades comunicativas; demonstrar criatividade; saber ouvir; demonstrar visão sistêmica.

Examinar manifestações e encaminhar soluções não são práticas que correspondem à dimensão plena e real das Ouvidorias. ROMANO (2008) refere que a interposição de tecnologias afasta e diminui as possibilidades de percepção do outro, ao mesmo tempo que essas carências são aí substituídas por pressupostos comunicativos dados pela natureza do próprio meio.

Os acessos à Ouvidoria modificam seu caráter midiático e injetam sentidos diferenciados nas manifestações recebidas, alterando tanto a relevância do assunto quanto a tempestividade e a efetividade da resposta. 
Por isso, a relação estreita entre competências técnicas e competências humanas requer conduções diferenciadas de análise das ocorrências, com adequação de linguagem, interferência em campos semânticos, traduções e transculturações de sentidos, enfim, uma complexa e sutil engenharia semiótica capaz de assegurar a eficácia do processo da comunicação.

\section{CONSIDERAÇÕES FINAIS}

A exposição do tema adota a reflexão (bio)ética enquanto uma atividade complexa que apresenta relação direta com a realidade e a materialidade no campo profissional do Ouvidor, sendo uma atividade ampla e renovável diante dos desafios da contemporaneidade. No campo dinâmico e complexo de debates da sociedade, a confluência entre os valores humanos, a bioética e os princípios de Ouvidoria, reafirma um sinal de esperança; bem como uma necessidade de ampliar as reflexões éticas no conjunto das competências técnicas e humanas do exercício profissional do Ouvidor. Este texto recolhe tais reflexões buscando eleger questões a serem repensadas, ou talvez ampliadas.

Os requisitos técnicos e pessoais envolvidos nas profissões precisam estar alinhados a uma conduta ética para afinar o discurso tecnocientífico através do gesto afetuoso, do olhar iluminado, do ouvido aguçado, da humanização da impessoalidade, da transformação da sisudez racional em sorriso compreensivo e fraternal (SANTIM, 2011). O Código de Ética, certamente, deve ser a partitura da harmonização entre o discurso científico e o discurso ético, formando a melodia do discurso profissional.

A instituição de Ouvidorias que respeitem o princípio de representação dos legítimos interesses do cidadão, com independência e autonomia, demonstra que é possível diminuir o grau de insatisfação do usuário e/ou consumidor, que deve deixar de ser considerado como um "detalhe" das organizações. Nessa perspectiva, a Ouvidoria assume uma função ativa de fomento da participação social, possibilitando o fortalecimento da democracia, o acesso à administração por meio das inter-relações dos indivíduos e da comunidade com os agentes institucionais.

Seguindo essa ótica, os princípios da Ouvidoria constituem-se como essência comum nas práticas tanto do setor público quanto da iniciativa privada. A observância de seus princípios promove ações socialmente responsáveis, incluindo condutas que refinam a ética do cuidado com o cidadão, agindo como uma instância que humaniza e aborda a condição de vulnerabilidade, visando a fortalecer a equidade sob a aplicação de direitos e deveres.

A Ouvidoria observa que as sociedades contemporâneas são nutridas de boas práticas, mas também acometidas no campo ético de muitas deficiências e fragilidades que desrespeitam as características constitutivas da pessoa humana. É preciso interagir com ações, sendo a Bioética da Proteção o instrumento fundamental de suporte reflexivo às Ouvidorias no sentido de se potencializarem como "dispositivo social" facilitador do diálogo, na tentativa de minimizar as assimetrias de poder e vulnerabilidade. Para tanto, um projeto para uma nova sociabilidade requer do Ouvidor competências técnicas e comportamentais, com visão ampliada sobre os referenciais éticos que consolidam o exercício de sua função. Assim, tais funções se apresentam na prática com sabedo- 
ria e inteligibilidade diante dos desafios contextualizados na proteção dos valores humanos e dos direitos de cidadania.

\section{REFERÊNCIAS}

\section{ASSOCIAÇÃO BRASILEIRA DE OUVIDORES/OMBUDSMAN ABO Nacional -CÓDIGO DE ÉTICA DO OUVIDOR.} Fortaleza, 1997. http://www.abonacional.org.br.

BARREIRO, Adriana Eugênia A.; HOSSNE, Demétrio; PENTEADO SOBRINHO, Florêncio dos Santos. Ética e Ouvidoria Pública. In: PEREZ, José Roberto R.; BARREIRO, Adriana Eugênia A.; PASSONE, Eric (Org.). Construindo a Ouvidoria no Brasil: avanços e perspectivas. Campinas, SP: Unicamp/Ouvidoria, 2011.

BERTACHINI, Luciana. Implantar Ouvidorias faz a diferença? Revista São Camilo, Brasil, São Paulo, v. 4, n. 16, p. 14, jul. 2013. 2012a.

Ouvidoria: conquistas, novos projetos e muitos desafios. Revista São Camilo, Brasil, São Paulo, p. 14, jan.

Convergências da Ouvidoria e Bioética na defesa dos Direitos Humanos. Direitos Humanos e Bioética [Recurso eletrônico on-line] organização III SEMIDI/UNISAL; coordenadores: Ivan Martins Motta, Lino Rampazzo, Pablo Jiménez Serrano-Lorena: III SEMIDI, 2015.

BRASIL. Lei n 10.294 de 20 de abril de 1999. Dispõe sobre a proteção e defesa do usuário do serviço público do Estado. Diário Oficial da União, Brasília, DF, 21 nov. p. 02, 1999.

Ministério do Trabalho e Emprego. Portaria ministerial n 397 de 9 de outubro de 2002. Classificação Brasileira de Ocupações. Identificação das ocupações no mercado de trabalho, para fins classificatórios junto aos registros administrativos e domiciliares. Brasília, DF.

CORTELLA, Mario Sergio. Qual é a tua obra: inquietações propositivas sobre gestão, liderança e ética. Petrópolis: Vozes, 2007.

FORNAZARO, M. I. Ouvidoria como Instrumento de Gestão. Clientesa, set. 2019. https://www.clientesa.com.br/artigos.

GRACIA, D. Pensar a Bioética: mente e desafios. São Paulo: Centro Universitário São Camilo; Loyola, 2010.568 p.

JENNINGS, Marie. The Guide to Good Corporate Citizenship. Cambrigde: Director Books, 1990.

MARQUES, Cláudia Lima et al. Comentários ao Código de Defesa do Consumidor. 2. ed. rev., atual. e ampl. São Paulo: Editora Revista dos Tribunais, 2005.

OLIVEIRA, João Elias de. A Ouvidoria e a Administração Pública. A Ouvidoria no Brasil. São Paulo: Associação Brasileira de Ouvidores, 2001.

Ouvidoria Pública Brasileira: a evolução de um modelo único. In: VISMONA, Edson Luiz (Org.). A Ouvidoria brasileira. Dez anos da Associação Brasileira de Ouvidores/Ombudsman. São Paulo: Imprensa Oficial do Estado de São Paulo; Associação Brasileira de Ouvidores/Ombudsman, 2005.

PESSINI, Leo; BERTACHINI, Luciana. Gestão Ética e liderança organizacional. In: PEREIRA, Luciane Lúcio; CHANES, Marcelo; GALVÃ̃O, Cláudia Raffa (Org.). Gestão em Saúde: tendências, inovações e perspectivas. São Paulo: Centro Universitário São Camilo, 2010.

ROMANO, R. Ética e Ouvidoria. Curso de Capacitação e Certificação de Ouvidores. São Paulo: Associação Brasileira de Ouvidores/Ombudsman, 2008.

SANTIN, S. A Ética e as Profissões: Uma reflexão filosofante. Santa Maria. 2011.

VERSPIEREN, Patrick. Peut-on refuser simultanément l'acharnement thérapeutique et l'euthanasie? Ethique, La vie en question, n. 6/7, p. 25-300, 1992/1993.

VISMONA, Edson Luiz et al. A Ouvidoria no Brasil. São Paulo: Imprensa Oficial do Estado; Associação Brasileira de Ouvidores, 2000.

A Ouvidoria no Brasil e seus Princípios. In: VISMONA, Edson Luiz; CLEMENTE, Júlia; MONTINI, Pedro Luiz. A Ouvidoria no Brasil. São Paulo: Imprensa Oficial do Brasil; Associação Brasileira de Ouvidores, 2001. p. 12 e 17.

WEBER, Max. A ética protestante e o "espírito" do capitalismo. São Paulo: Companhia das Letras, 2004.

YAZBEK, Maria Carmelita. Serviço Social e pobreza. Revista Katálysis, Florianópolis, v. 13, n. 2, p. 153-154, dez. 2010.

68 | Revista Científica da Associação Brasileira de Ouvidores/Ombudsman - Ano 3 - n $3-2020$ 